\title{
Effects of subclinical hypothyroidism treatment on psychiatric symptoms, muscular complaints, and quality of life
}

\author{
Efeitos do tratamento do hipotiroidismo subclínico sobre sintomas \\ psiquiátricos, queixas musculares e qualidade de vida
}

Vaneska Spinelli Reuters', Cloyra de Paiva Almeida', Patrícia de Fátima dos Santos Teixeira', Patrícia dos Santos Vigário', Márcia Martins Ferreira' ', Carmen Lucia Natividade de Castro², Marco Antônio Brasil ${ }^{3}$, Antônio José Leal da Costa ${ }^{4}$, Alexandru Buescu', Mário Vaisman'

${ }^{1}$ School of Medicine, Universidade Federal do Rio de Janeiro (UFRJ), and Endocrinology Service, Hospital Universitário Clementino Fraga Filho (HUCFF), Rio de Janeiro, RJ, Brazil ${ }^{2}$ Division of Physical Medicine and Rehabilitation, HUCFF-UFRJ, Rio de Janeiro, RJ, Brazil ${ }^{3}$ Department of Psychiatry and Forensic Medicine, UFRJ, Rio de Janeiro, RJ, Brazil ${ }^{4}$ Public Health Study Nucleus, UFRJ, Rio de Janeiro, RJ, Brazi

Correspondence to: Vaneska Spinelli Reuters Universidade Federal do Rio de Janeiro Serviço de Endocrinologia Av. Prof. Rodolpho Paulo Rocco, 255 21941-913 - Rio de Janeiro, RJ, Brazil vsreuters@hotmail.com

Received on Feb/6/201 Accepted on Feb/23/2012

\section{ABSTRACT}

Objectives: To evaluate the impact of subclinical hypothyroidism (sHT) treatment on health-related quality of life (QoL), psychiatric symptoms, clinical score, and muscle function. Materials and methods: In this randomized double-blind study, patients were assigned either to treatment $(n=35)$ or placebo $(n=36)$. Clinical and psychiatric symptoms were assessed by the Zulewski, Hamilton and Beck scales. OoL was assessed by the SF-36 questionnaire. Assessments of quadriceps (QS) and inspiratory muscle (IS) strength were performed by a chair dynamometer and a manuvacuometer. Results: Treatment improved IS $(+11.5 \pm 17.2 ; p=0.041)$, as did OoL domains "Pain" and "Role Physical" (+19.7 $\pm 15.2,0.039$ and +22.1 $\pm 47.5, p=0.054$; respectively). Clinical and psychiatric symptoms showed similar responses to both interventions. Conclusions: sHT treatment improved IS and physical aspects of $\mathrm{QoL}$, despite no impact in other muscle parameters. Clinical score, psychiatric symptoms, and SF-36 domains, based on mental dimensions of QoL may be more susceptible to "placebo effect" in patients with sHT. Arq Bras Endocrinol Metab. 2012;56(2):128-36

Keywords

Anxiety; depression; quality of life; levothyroxine

\section{RESUMO}

Objetivos: Avaliar o impacto do tratamento do hipotireoidismo subclínico (sHT) na qualidade de vida relacionada à saúde $(\mathrm{QoL})$, aos sintomas psiquiátricos, ao escore clínico e à função muscular. Materiais e métodos: Em um ensaio randomizado duplo-cego, pacientes foram randomizados para tratamento $(n=35)$ ou uso de placebo $(n=36)$. Sintomas clínicos e psiquiátricos foram acessados por meio das escalas de Zulewski, Hamilton e Beck. A QoL foi avaliada pelo questionário SF-36. Medidas da força de quadríceps (QS) e inspiratória (IS) foram obtidas por um dinamômetro de cadeira e um manovacuômetro. Resultados: 0 tratamento melhorou a IS $(+11,5 \pm 17,2 ; p=0,041)$, assim como os domínios "Dor" e "Aspectos Físicos" da QoL (+19,7 $\pm 15,2,0,039$ e $+22,1 \pm 47,5, p=0,054$, respectivamente). Sintomas clínicos e psiquiátricos demonstraram respostas similares a ambas as formas de intervenção. Conclusões: Tratamento do sHT melhorou IS e aspectos físicos da QoL, apesar de não ter impacto em outros parâmetros musculares. Escore clínico, sintomas psiquiátricos e domínios do SF-36 que focam em dimensões mentais podem ser mais suscetíveis ao "efeito placebo" em pacientes com sHT. Arq Bras Endocrinol Metab. 2012;56(2):128-36

Descritores

Ansiedade; depressão; qualidade de vida; levotiroxina 


\section{INTRODUCTION}

$\mathrm{T}$ hyroid hormones have an important role in many organic functions and their deficiency cause a wide spectrum of clinical presentations and symptoms. Neuromuscular manifestations are well established in overt hypothyroidism $(\mathrm{OH})$, and impaired muscle function is frequently observed $(1,2)$. Thyroid hormone deficiency may also interfere substantially with various aspects of physical, mental and social well-being (3).

The evidence for improvement of psychiatric symptoms with hormonal treatment (levothyroxine) of $\mathrm{OH}$, and the use of triiodothyronine $\left(\mathrm{T}_{3}\right)$ to potentiate the response to treatment of depressive disorders suggest a direct relationship between thyroid hormones and psychiatric symptoms (4). Neurobiological evidence seems to corroborate the hypothesis of an organic basis of the effects of thyroid hormone on the brain and on psychiatric symptoms (5).

There is some evidence that subclinical hypothyroidism ( $\mathrm{sHT}$ ) may also be responsible for findings classically described in $\mathrm{OH}$ (6). Symptoms and signs of hypothyroidism have been frequently found in sHT patients, as reported by many authors (6-10), including our group (11).

The influence of sHT on health status or quality of life (QoL) is not well established. Some population studies showed no differences in health-related QoL perception between sHT patients and a normal, healthy population $(12,13)$, while another outpatient study demonstrated impairment in sHT compared with normal controls (14).

There is little information about neuromuscular dysfunction in SHT. Some authors have described greater frequency of neuromuscular symptoms or muscle dysfunction on electromyography in sHT patients $(7,9,11,15)$. Proximal muscle strength seems to be impaired in sHT, and our group previously published a cross-sectional study in which there was greater prevalence of neuromuscular complaints and altered muscle strength in sHT compared with a control group (11).

The aim of the present study was to evaluate some physical and psychological aspects possibly related to sHT, based on the impact of levothyroxine (LT4) replacement and restoration of euthyroidism on health-related quality of life, psychiatric symptoms, clinical score, and muscle function of patients with sHT, in a double-blind, randomized, placebo-controlled trial.

\section{PATIENTS AND METHODS}

\section{Subjects}

Patients were recruited from the Outpatient Clinic of the Hospital Universitário Clementino Fraga Filho (HUCFF) of the Universidade Federal do Rio de Janeiro (UFRJ). To be enrolled, sHT patients had to have two laboratory serum determinations with a minimum interval of six weeks, both with results of serum Thyrotropin (TSH) levels above the normal upper limit $(4.0 \mu \mathrm{UI} / \mathrm{mL})$, and free thyroxine (FT4) in the normal range $(0.9-1.8 \mathrm{ng} / \mathrm{dL})$. If sHT developed after hyperthyroidism treatment, a confirmation of laboratory euthyroidism for at least one year before the development of sHT, was mandatory. Subjects with chronic diseases or using drugs that may influence thyroid function were excluded, as did patients with severe psychiatric disturbances. Patients who attended school for less than 3 years were also excluded. For the evaluation of muscular complaints we also excluded subjects using drugs or showing other diseases that could influence neuromuscular function. All participants filled out and signed a written informed consent for the study, which was approved by the Ethics Committee of the institution ( $\left.n^{\circ} 12 / 01\right)$.

\section{Clinical and psychiatric evaluations}

All subjects were evaluated by means of a clinical questionnaire, and underwent physical examination. Psychiatric tests were performed by the same psychiatrist throughout the study, in all participants. These tests included Hamilton scale for anxiety and depression, and Beck Depression Inventory (BDI) for evaluation of psychopathological symptoms (16-18).

\section{Signals and symptoms of hypothyroidism - Clinical score}

Disease-specific signals and symptoms were assessed by the Billewicz scale modified by Zulewski e cols. (19), as has been widely used in studies of hypothyroidism. The scale comprises 12 clinical signals and symptoms of hypothyroidism: periorbital puffiness, constipation, weight gain, cold skin, paresthesia, hoarseness, dry skin, diminished sweating, impaired hearing, coarse skin, slow movements, and delayed ankle reflex. Signals and symptoms are worth one point (1) when they are present, or zero (0) when they are absent. Thus, the maximum score is 12 points. Scores lower than three points $(<3)$ are expected in euthyroid subjects; scores between three and five points $(3$ to $<5)$ are expected in 
patients with sHT, and scores equal five (5) or higher are expected in patients with $\mathrm{OH}$.

\section{Quality of life assessment}

The SF-36 (Medical Outcomes Study 36-Item Short-Form Health Survey) was used to assess the QoL of the studied population, in its translated and validated Portuguese version (20). The SF-36 is a generic QoL assessment instrument composed of 36 items, divided into eight scales or dimensions: physical function, general health, vitality, mental health, social function, role-emotional, role-physical and bodily pain. Answers are presented on a Likert scale. Each scale can range from zero $(0)$ to 100 points, in which 100 points represents the maximum score and the best satisfaction with QoL, while zero points represent the lowest score and the highest dissatisfaction with QoL.

\section{Muscular evaluation}

Evaluation of muscle function was performed by an experienced physiatrist who did not have previous information about the thyroid status of the participants.

Muscle strength was evaluated for inspiratory and peripheral muscles. For the pelvic and scapular girdles, the manual muscle test (MMT) was performed, with the patient in appropriate position: the grade was estimated by the resistance offered to the examiner, as described previously $(21,22)$. Isometric Quadriceps Strength (QS; Kgf) was quantified in a standardized way by means of a chair dynamometer (IsoTeste Kroman-Thrigger, Brazil) (23). The mean of six voluntary maximum isometric contractions (three of the right side and three of the left side) was calculated, and the result was expressed as a percentage of the reference values, according to the National Isometric Muscle Strength (NIMS) (24), based on gender, age, height and weight.

Inspiratory muscle strength (IS) was assessed by measuring the Maximum Static Inspiratory Mouth Pressure (PImax; $\mathrm{cm} \mathrm{H}_{2} \mathrm{O}$ ). Pressure was measured near residual volume according to the Picado method (25), using a manuvacuometer. The mean of three attempts was used to calculate the percentage of the expected value for the age and gender, based on the formula proposed by Black and Hyatt (26).

\section{Study protocol}

After baseline evaluations, patients were randomly assigned to L-T4 replacement $(\mathrm{n}=35)$ or placebo $(\mathrm{n}=$
36 ) in a double-blind protocol. Similar tablets containing L-T4 or placebo were precisely counted and given to each patient. Randomization without blocks was carried out after stratification of the patients by TSH levels. Thus, patients in level 1 had TSH in the range of $>4.0-8.0 \mu \mathrm{UI} / \mathrm{mL}$, patients in level 2 had TSH in the range of $>8.0-12.0 \mu \mathrm{UI} / \mathrm{mL}$, and those in level $3 \mathrm{had}$ $\mathrm{TSH}>12.0 \mu \mathrm{UI} / \mathrm{mL}$.

The initial dose of the tablets was based on TSH levels. Patients in level 1 started replacement with $25 \mathrm{mcg}$ of L-T4, and those in levels 2 and 3 started with 50 and $75 \mathrm{mcg}$, respectively. All patients returned after two months for dose adjustment and evaluation of adhesion to the study protocol. One physician, not blind and not involved in the clinical evaluation of the patients, was responsible for this adjustment. Patients were then evaluated every three months after becoming euthyroid. If a new adjustment of the dose became necessary, the elapsed period was not considered as time of euthyroidism.

Patients taking placebo completed a similar protocol, with adjustment of dose by TSH levels. A reevaluation of the clinical questionnaire and all tests was obtained after six months of euthyroidism. If any patient initiated treatment with drugs or developed diseases that influenced thyroid status, muscular or neuropsychiatric function, he or she was excluded throughout the study. Patients that did not adhere to the protocol, those who progressed to overt hypothyroidism or needed doses larger than 75 mcg were also excluded from study. No adherence to the protocol was assumed when more than $20 \%$ of total tablets for the period, were returned twice.

\section{Laboratory assays}

Serum TSH, FT4 and anti-thyroperoxidase antibodies (TPO-Ab) were measured by immunochemiluminescence (DPC - Diagnostic Products Corporation/ Immulite $\left.2000^{\circledR}\right)$. Reference ranges for TSH and FT4 were $0.4-4.0 \mu \mathrm{UI} / \mathrm{mL}$ and $0.9-1.8 \mathrm{ng} / \mathrm{dL}$, respectively. Levels of TPO-Ab $>35 \mathrm{UI} / \mathrm{mL}$ were considered positive. The intra-assay coefficients of variation were $3.8 \%-12.5 \%, 4.4 \%-7.5 \%$ and $4.3 \%-5.6 \%$ for TSH, FT4, and TPO-Ab, respectively. Inter-assay coefficients of variation were $4.6 \%-12.5 \%, 4.8 \%-9.0 \%$ and $7.8 \%-10.5 \%$ for TSH, FT4, and TPO-Ab, respectively.

Serum creatine phosphokinase (CPK) and lactic dehydrogenase $(\mathrm{LDH})$ were determined by an automated kinetic method UV- $37^{\circ} \mathrm{C}$, Kit Boehringer - Dimension Clinical Chemistry System. Reference ranges 
for CPK are 21-215 U/L for women and 35-232 U/L for men. $\mathrm{LDH}$ reference range is $100-190 \mathrm{U} / \mathrm{L}$.

\section{Statistical analysis}

Baseline characteristics were described using means \pm Standard Deviation (SD) and proportions. Continuous variables were compared between the two study groups by Student's $t$ test or Mann-Whitney's test, according data distribution. Similarly, comparison involving proportions were based on $X^{2}$ or Fisher's exact test.

The primary outcome (indicative of L-T4 effect) was defined as the variation in the tests, calculated as the difference between the 6-month and baseline value observed for each patient who completed follow-up. The effect of L-T4 was then assessed by comparing mean variations in each test between the two groups, based on a per-protocol approach. Besides, Student's $t$ test or Wilcoxon tests were performed to detect possible significant variation in a single study group throughout the prospective intervention.

Regarding psychiatric tests, negative variations were associated with improvement in the scores, detected as reduction in the level of depression and anxiety symptoms.

As to the QoL evaluation, positive variations were associated with improvement in the health status of the patient.

\section{RESULTS}

Seventy one patients were included in the clinical trial to study the effects of LT-4 replacement on clinical score, psychiatric symptoms, and QoL (L-T4 group $=35$; placebo $=36)$. A subgroup of 52 patients $(\mathrm{L}-\mathrm{T} 4$ group $=$ 25 ; placebo $=27$ ) was assessed for muscular complaints. Baseline clinical and socio-demographic characteristics were similar in both intervention groups (Table 1 ).

The subgroup of patients analyzed for muscular complaints showed high prevalence of sedentary li- festyle, which was similar in both randomized groups (79.2\% in the L-T4 treated group, and $77.8 \%$ in the placebo group). The intervention groups were also similar in relation to tobacco use $(12.0$ vs. $7.4 \% ; \mathrm{p}=$ $0.662)$, and mean body mass index (BMI) $(27.7 \pm 4.8$ vs. $26.7 \pm 5.9 ; \mathrm{p}=0.524)$.

Segment losses throughout the study are shown in table 2. Exclusion of these patients did not generate distortions in the initial randomization characteristics, since comparisons between baseline characteristics of the patients that concluded the study, for each intervention, were similar (Table 3 ).

At six months, improvements in clinical scores, psychiatric symptoms and the domain "Role emotional" in the QoL evaluation were detected in the L-T4 replacement group (Table 4). However, the same pattern of improvement was detected in the group that received placebo, with statistical significance for anxiety symptoms and self-related depressive symptoms (measured by Beck questionnaire). The comparison between the effects of L-T4 and placebo use on the variables assessed in psychiatric and emotional aspects showed no statistical differences, except for the domain "role emotional" that showed a trend of greater improvement with L-T4 replacement $(+27.7 v s .+2.6 ; \mathrm{p}=$ $0.070)$. The domains "mental health" and "social function" were not influenced by the interventions.

In the evaluation of the SF-36 domains involved in physical health ("general health"; "physical function"; "role pain"; "role physical" and "vitality"), an improvement in the domain "role pain" with L-T4 replacement was detected, and it was statistically different from the worsening observed with placebo use (Table 4 ). A trend of improvement was also detected in "general health" and "role physical" with L-T4 replacement, which was statistically different from the effect of placebo use in this last domain. The domains "vitality" and "physical function" were not influenced by the interventions.

Table 1. Baseline characteristics of randomized patients in each intervention group

\begin{tabular}{|c|c|c|c|c|c|c|}
\hline & \multicolumn{3}{|c|}{ Whole group } & \multicolumn{3}{|c|}{ Muscular study subgroup } \\
\hline & L-T4 (n = 35) & $P(n=36)$ & p-value & L-T4 (n = 25) & $P(n=27)$ & p-value \\
\hline Age (years) & $49.3 \pm 10.3$ & $50.7 \pm 11.4$ & 0.228 & $52.6 \pm 8.1$ & $49.5 \pm 12.2$ & 0.291 \\
\hline Gender & $F=30, M=3$ & $F=32, M=4$ & 0.115 & $F=22, M=3$ & $F=27$ & 0.104 \\
\hline Menopause (\%) & 63.3 & 47.7 & 0.191 & 53.3 & 46.7 & 0.413 \\
\hline Low level of education (\%) & 34.3 & 33.3 & 0.274 & 36.0 & 22.2 & 0.362 \\
\hline TSH ( $(\mu \mathrm{Ul} / \mathrm{mL})$ & $7.3 \pm 2.3$ & $7.6 \pm 2.7$ & 0.924 & $8.2 \pm 2.7$ & $7.8 \pm 2.9$ & 0.680 \\
\hline Free $T_{4}(\mathrm{ng} / \mathrm{dL})$ & $1.1 \pm 0.3$ & $1.1 \pm 0.2$ & 0.962 & $1.1 \pm 0.2$ & $1.1 \pm 0.3$ & 0.645 \\
\hline TPO-Ab (\%) & 67.9 & 69.0 & 0.928 & 60.0 & 70.4 & 0.562 \\
\hline
\end{tabular}


Table 2. Segment losses throughout the study

\begin{tabular}{|c|c|c|c|}
\hline & Sample (N) & L-T4 & Placebo \\
\hline $\begin{array}{l}\text { Initially randomized } \\
\text { patients }\end{array}$ & 71 & 35 & 36 \\
\hline $\begin{array}{l}\text { Losses through the } \\
\text { study }\end{array}$ & $\begin{array}{c}14 \\
\text { Disease progression* }= \\
(\mathrm{L}-\mathrm{T} 4=4 ; \text { placebo }=3) \\
\text { No adherence }=6 \\
(\mathrm{~L}-\mathrm{T} 4=3 ; \text { placebo }=1) \\
\text { Hyperthyroidism }=1(\mathrm{~L}-\mathrm{T} 4=1) \\
\text { Drugs or diseases }{ }^{\star \star}=2(\mathrm{~L}-\mathrm{T} 4=1)\end{array}$ & 10 & 4 \\
\hline $\begin{array}{l}\text { Patients that concluded } \\
\text { 6-month follow-up }\end{array}$ & 57 & 25 & 32 \\
\hline
\end{tabular}

* Patients who developed overt hypothyroidism or needed more than a daily dose of $75 \mathrm{mcg}$ of L-T4 to restore euthyroidism; ${ }^{*}$ One patient needed to use statin, and another developed rheumatic disease.
There was a significant improvement in IS with L-T4 replacement. No influence of L-T4 replacement on QS, pelvic and scapular girdle strength (PSGS), and muscular enzymes (Table 4) could be detected.

Positive correlations between baseline IS and SF-36 domains, which evaluated physical aspects of health status, were detected (Table 5). Lower scores in the "role pain" domain were associated with higher levels of serum LDH and lower QS. PSGS was adequately correlated with the majority of SF-36 domains that assessed physical aspects (Table 5).

Table 3. Baseline characteristics of patients that concluded the study, according to the intervention group

\begin{tabular}{|c|c|c|c|c|c|c|}
\hline & \multicolumn{6}{|c|}{ Patients that concluded the study } \\
\hline & \multicolumn{3}{|c|}{$\begin{array}{c}\text { Whole group (clinical score, psychiatric symptoms and } \\
\text { QoL evaluation) }\end{array}$} & \multicolumn{3}{|c|}{ Muscular study subgroup } \\
\hline & L-T4 (n = 25) & $P(n=32)$ & p-value & L-T4 $(n=14)$ & $P(n=23)$ & p-value \\
\hline Age (years) & $51.7 \pm 9.2$ & $48.3 \pm 11.7$ & 0.632 & $55.0 \pm 8.0$ & $48.91 \pm 12.6$ & 0.090 \\
\hline Gender & $F=22, M=3$ & $F=32$ & 0.085 & $F=12, M=2$ & $F=23, M=0$ & 0.137 \\
\hline Menopause (\%) & 69.2 & 43.7 & 0.319 & 83.3 & 52.2 & 0.139 \\
\hline Body mass index (kg/m²) & $26.4 \pm 2.5$ & $27.1 \pm 6.3$ & 0.708 & $27.7 \pm 4.8$ & $26.7 \pm 5.9$ & 0.524 \\
\hline Low level of education (\%) & 44 & 21 & 0.105 & 21.4 & 36.4 & 0.060 \\
\hline $\mathrm{TSH}(\mu \mathrm{UI} / \mathrm{mL})$ & $7.1 \pm 1.7$ & $7.5 \pm 2.6$ & 0.512 & $7.4 \pm 1.8$ & $7.0 \pm 2.5$ & 0.662 \\
\hline Free $\mathrm{T}_{4}(\mathrm{ng} / \mathrm{dL})$ & $1.1 \pm 0.1$ & $1.1 \pm 0.2$ & 0.793 & $1.07 \pm 0.2$ & $1.09 \pm 0.2$ & 0.803 \\
\hline TPO-Ab (\%) & 63.6 & 63.7 & 0.684 & 57.1 & 30.4 & 0.169 \\
\hline
\end{tabular}

Table 4. Mean variations in the studied variables at the end of study

\begin{tabular}{|c|c|c|c|c|c|}
\hline & L-T4 & P-Value* & Placebo & P-Value ${ }^{\star \star}$ & P-Value \\
\hline GH & $6.5 \pm 13.2$ & 0.068 & $7.4 \pm 18.3$ & 0.065 & 0.863 \\
\hline PhyF & $3.7 \pm 17.2$ & 0.425 & $1.9 \pm 21.6$ & 0.669 & 0.799 \\
\hline RPhy & $\underline{22.1 \pm 47.5}$ & 0.054 & $-8.0 \pm 35.1$ & 0.266 & $\underline{0.023}$ \\
\hline SF & $1.3 \pm 24.4$ & 0.823 & $0.3 \pm 33.1$ & 0.927 & 0.939 \\
\hline RE & $\underline{27.7 \pm 47.5}$ & $\underline{0.026}$ & $2.6 \pm 40.8$ & 0.221 & 0.070 \\
\hline $\mathrm{MH}$ & $0.2 \pm 28.2$ & 0.974 & $5.6 \pm 22.1$ & 0.202 & 0.476 \\
\hline VITA & $-2.3 \pm 22.9$ & 0.679 & $0.2 \pm 21.1$ & 0.965 & 0.719 \\
\hline Rpain & $\underline{19.7 \pm 15.2}$ & $\underline{0.039}$ & $-4.6 \pm 16.9$ & 0.712 & $\underline{0.046}$ \\
\hline Score & $-\underline{0.5 \pm 1.2}$ & $\underline{0.050}$ & $\underline{-0.8 \pm 1.6}$ & $\underline{0.010}$ & 0.475 \\
\hline IS & $+11.5 \pm 17.2$ & $\underline{0.041}$ & $-2.2 \pm 18.0$ & 0.611 & 0.126 \\
\hline QS & $+5.3 \pm 11.2$ & 0.110 & $+0.8 \pm 19.6$ & 0.849 & 0.451 \\
\hline CK & $+43 \pm 120$ & 0.514 & $+30 \pm 108$ & 0.206 & 0.769 \\
\hline LDH & $-12.1 \pm 40.3$ & 0.337 & $0.2 \pm 43.0$ & 0.965 & 0.246 \\
\hline PSGS & $+0.3 \pm 1.9$ & 0.660 & $+0.4 \pm 2.3$ & 0.632 & 0.809 \\
\hline Hamilton A & $-3.6 \pm 5.1$ & $\underline{0.006}$ & $-\underline{-4.1 \pm 7.6}$ & $\underline{0.013}$ & 0.832 \\
\hline Hamilton D & $-1.6 \pm 2.8$ & $\underline{0.020}$ & $-0.6 \pm 2.9$ & 0.288 & 0.245 \\
\hline Beck & $-2.4 \pm 5.8$ & $\underline{0.054}$ & $\underline{-2.1 \pm 4.8}$ & $\underline{0.042}$ & 0.834 \\
\hline
\end{tabular}

GH: general health; PhyF: physical function; Rpain: Role pain; RPhy: role physical; VITA: vitality; SF: social function; RE: role-emotional; MH: Mental health; IS: inspiratory strength; QS: quadriceps strength; PSGS: pelvic and scapular girdle strength. ${ }^{*}$ Effect of L-T4 treatment; ${ }^{* *}$ Effect of placebo treatment; ${ }^{* \star}$ Comparison of L-T4 and placebo responses to treatment. 
Table 5. Correlation indexes between the variables that assessed muscle function and SF-36 domains that evaluated physical aspects of health status

\begin{tabular}{|c|c|c|c|c|c|}
\hline \multirow{2}{*}{ SF-DOMAINS } & \multicolumn{5}{|c|}{ Muscle function } \\
\hline & $\mathbf{Q S}^{\mathbf{a}}$ & $\mathbf{I S}^{\mathrm{b}}$ & PSGS $^{c}$ & $\mathbf{C K}^{\mathrm{d}}$ & $\mathbf{L D H}^{\mathbf{e}}$ \\
\hline RPhys $^{f}$ & 0.044 & $+0.363^{\star}$ & $\underline{-0.260^{\star \star}}$ & -0.226 & -0.300 \\
\hline Ppain ${ }^{9}$ & $+0.257^{\star \star}$ & +0.144 & $-0.222^{\star \star}$ & -0.207 & $\underline{-0.370^{*}}$ \\
\hline PhyF $^{\text {h }}$ & +0.050 & $+0.363^{\star}$ & $\underline{-0.260^{*}}$ & -0.227 & -0.194 \\
\hline Vita' & +0.181 & $+0.372^{*}$ & -0.194 & 0.055 & -0.200 \\
\hline GHi & -0.053 & $+0.255^{\star \star}$ & $\underline{-0.321^{*}}$ & -0.220 & $-0.262^{\star \star}$ \\
\hline
\end{tabular}

${ }^{*} p$-value $<0.05$; ${ }^{* *} p$-values $>0.05$ and $<0.100$.

a: quadriceps strength; b: inspiratory strength; c: pelvic and scapular girdle strength; d: creatine phosphokinase; e: lactate dehydrogenase; f: role physical; g: Role pain; h: physical function; i: vitality; j: general health.

\section{DISCUSSION}

In the present study, the effects of L-T4 treatment in patients with sHT were assessed in a double-blind randomized placebo-controlled trial. Physical aspects were evaluated by estimation of muscle strength, and by assessing hypothyroidism symptoms and signs by means of a scoring system. Psychological aspects were evaluated by assessing health-related quality of life and scales of psychiatric symptoms. The authors examined health-related quality of life, psychiatric and hypothyroidism symptoms using validated instruments, and evaluated muscular function with specific laboratory tests.

There are very few studies that evaluated muscular function in $\operatorname{sHT}(7,9,11,15)$, and none included clinical signs and symptoms, psychiatric complaints, and health status in the same study. We believed that some psychological aspects of thyroid hypofunction, when present in sHT, may be influenced by physical findings, as suggested by the association between physical aspects of quality of life, in the SF-36 evaluation, and muscular function, specially IS, in the present study.

Kong and cols. and Bono and cols. studied psychiatric symptoms in patients with mean TSH levels similar to the present study $(7.72 \pm 1.53 \mu \mathrm{UI} / \mathrm{mL}$ and $8.5 \pm$ $5.7 \mu \mathrm{UI} / \mathrm{mL}$, respectively) $(10,27)$. Both groups obtained results similar to those obtained in our study. Jorde and cols. studied patients with lower mean TSH (5.72 $\pm 1.68 \mu \mathrm{UI} / \mathrm{mL}$ ), and did not demonstrated impact of sHT treatment in emotional function and hypothyroid symptoms, either (28). Besides the possible relationship between the amount of symptoms and TSH serum levels, some authors related neuropsychiatric changes to the time evolution of the thyroid disease (29).
Up to now, only three studies were published with designs similar to the one used by our group, applying the same scales to assess the intensity of psychiatric symptoms (HAM-D, HAM-A, and BDI). From these, two found no differences between the results before and after levothyroxine treatment $(28,30)$. Baldini and cols. found no significant changes in HAM-A and HAM-D scores after 3 months of treatment, although they found higher scores in the studied population before treatment (30). Probably, the differences between our study and theirs may be caused by different inclusion criteria, since their sample was constituted by patients with goiter that were already in treatment. Also, they conducted a relatively shorter (three months) follow-up.

Jorde and cols. showed no improvement in depressive symptoms after one year of treatment (according to the BDI) in a group of older individuals (mean age greater than 60 years old) from the overall population, without complaints, and with lower serum levels of TSH than our patients (28). Our sample was different from that, since it included patients from a hospital environment, with higher TSH, and more initial complaints of depression, as previously demonstrated $(31,32)$.

In short, despite an improvement in psychiatric symptoms detected with L-T4 replacement, treatment effect was not different from the placebo effect. The effect of sHT treatment in those SF-36 domains, which evaluate psychiatric and emotional aspects, such as "mental health" and "social function", did not differ from the placebo effect, either. The only exception was the domain "role emotional", with a trend of greater improvement with L-T4 replacement. Based on these results, it does not seem that L-T4 truly improves mental aspects of QoL and psychiatric symptoms in sHT patients, what is supported by the similar response found for the use of L-T4 or placebo. This similar response suggests that patients are particularly susceptible to the effect of being treated, no matter what is being used ("placebo effect").

The evaluation of muscular complaints demonstrated an improvement in IS that was significantly different from the deterioration detected with placebo use. Little has been published in the literature about pulmonary function of patients with $\mathrm{sHT}$, with conflicting data: one study showed lower spirometric parameters in 120 sHT patients, in comparison with euthyroid subjects (33), and another showed no changes with L-T4 replacement (34). Our group previously demonstrated that, in patients with sHT, IS was lower, and was as- 
sociated with muscular symptoms and altered manual muscle test results (22). In fact, we also detected that almost all SF-36 domains that evaluated physical aspects of health status improved with L-T4 replacement, specially "role pain" and "role physical", since the improvement in these domains with L-T4 really differed from the placebo effect. Also, we demonstrated positive correlations between baseline IS and SF-36 domains that evaluated physical aspects of health status. These results suggest that L-T4 replacement tends to improve some physical aspects in sHT, as observed with the improvement of some physical aspects of health-related quality of life and IS improvement, different from the response obtained with placebo.

The use of a randomized double-blind placebo-controlled design safeguarded the two groups from similar interferences and approaches throughout the study. The results showed that the two groups (L-T4 use and placebo use) had similar characteristics at baseline. Also, the stratification by TSH levels, before randomization, generated two groups of intervention with similar baseline serum TSH levels.

To our knowledge, four studies with double-blind, placebo-controlled trial design evaluating QoL, have been published until now $(10,28,35,36)$. Jaeschke and cols., in 1996, described slight nonsignificant improvement that was similar for L-T4 and placebo-treated groups in all domains of QoL, as tested by the Chronic Thyroid Questionnaire (CTQ) and Sickness Impact Profile (SIP) (35). These authors included older participants with mean age of $68.0 \pm 9.4$ for L-T4 and 68.0 \pm 6.4 years for the placebo group, a higher range than that of the present study. Older people usually have more complaints than younger people, and these complaints may have causes other than thyroid dysfunction. Consequently, improvement with L-T4 may not be detected. Recently, some studies had demonstrated that mild elevations in serum TSH levels in older patients have a protective effect in the cardiovascular system and mobility parameters (37). Besides, sHT may not be associated with cognitive impairment, depression or poor quality of life (QoL) in elderly subjects (38).

Another double-blind placebo-controlled trial was performed with outpatients by Kong and cols. (10). They applied two general questionnaires: version GHQ-30 of the General Health Questionnaire and the Hospital Anxiety and Depression Scale (HADS). They found little influence of treatment in QoL for both the L-T4 and placebo group (10). Both questionnai- res emphasize psychosocial aspects of QoL, and as the present results, mental dimensions tended to respond similarly to L-T4 and placebo use. Another study, by Jorde and cols., with sHT individuals recruited from an epidemiological health survey, did not observe important modifications in QoL scores neither in L-T4 nor in the placebo group after one year of follow-up (28). These authors applied version GHQ-30 of the General Health Questionnaire (GHQ-30), and included healthy older patients (mean age $>60$ years old) with lower baseline serum TSH levels $(\mathrm{L}-\mathrm{T} 4=5.81 \pm 1.76 \mu \mathrm{UI}$ / $\mathrm{mL}$ and placebo $=5.32 \pm 1.25 \mu \mathrm{UI} / \mathrm{mL})$. They concluded that there was no need to treat these kinds of patients, at least in relation to cognitive and emotional function (28).

Mean serum TSH of our sample did not differ from that presented in sectional surveys that studied the prevalence of subclinical thyroid diseases in different populations, including one in the city of Rio de Janeiro (39).

Razvi and cols. recently published a double-blind placebo-controlled trial with an urban population of the $\mathrm{UK}$, with mean age of $53.8 \pm 12$ years old and mean TSH level of $6.6 \mu \mathrm{UI} / \mathrm{mL}(36)$. These authors applied the SF-36, but did not find any significant changes in health status both for L-T4 and placebo groups after 12 weeks of treatment. In the same study, these authors did not observe any significant change in treatment satisfaction assessed by The Underactive Thyroid Treatment Satisfaction Questionnaire (ThySQ), either (36). On the other hand, these authors observed reduced perception of the negative impact of hypothyroidism on total QoL with L-T4 substitution, using the Underactive Thyroid-Dependent QoL (ThyDQoL) (36). They also found a significant reduction in the frequency of patients reporting tiredness in the Underactive Thyroid Symptom Checklist (ThySC) (36).

Symptoms scales created to assess the severity of hypothyroidism have been also used in sHT. In present study, we found a non-significant change in mean Zullewski score. Six double-blind placebo-controlled trials evaluated hypothyroid symptoms until now $(7,10,35,38,40)$. Cooper and cols., in 1984, applied the Billewicz score, and found that symptoms persisted or intensified with placebo treatment, but tended to improve with L-T4 (7). However, patients included in this study were previously treated for hyperthyroidism, and had a baseline serum TSH levels (L-T4 $=10.8 \pm 2.2$ $\mu \mathrm{UI} / \mathrm{mL}$ and placebo $=11.1 \pm 3.2 \mu \mathrm{UI} / \mathrm{mL})$, greater than in present study (7). 
Meier and cols., in 2000, also used Billewicz and Zullewski scores to assess hypothyroidism symptoms, and demonstrated a significant improvement in both questionnaires with L-T4 substitution compared with placebo when initial serum TSH levels was greater than $12 \mu \mathrm{UI} / \mathrm{mL}$, but not when patients had lower initial TSH levels $(\leq 12 \mu \mathrm{UI} / \mathrm{mL})(40)$. These findings suggest a possible influence of higher baseline serum TSH levels in response to treatment. However, another study conducted by Jaeschke and cols. that evaluated the same symptoms that Cooper and cols. did (cramps, dry skin, intolerance to cold, constipation, energy and fatigue), did not find significant changes with L-T4 or placebo use, despite higher baseline serum TSH levels $(\mathrm{L}-\mathrm{T} 4=12.1 \pm 6.8$ and placebo $=9.4 \pm 3.1 \mu \mathrm{UI} /$ $\mathrm{mL})(7,35)$. Kong and cols. observed improvement in hypothyroidism symptoms of fatigue, concentration and dry skin similar for L-T4 and placebo use after six months, in sHT patients with baseline serum TSH closer to that observed in our study (10). Jorde and cols. applied a 19-item questionnaire to assess hypothyroid symptoms and did not find any differences in response to L-T4 and placebo use (28). Nyström and cols., in a population study in Sweden, found a significant improvement in symptom score after 6-months of L-T4 replacement (4l).

Neuromuscular manifestations are frequent in overt hypothyroidism. Although some transversal studies showed greater prevalence of neuromuscular abnormalities in sHT $(7,9,11,15)$, little has been published about the effect of L-T4 substitution on them. To our knowledge, there is no double-blind placebo-controlled trial that evaluated muscle function until the present moment. In the present study, inspiratory strength had significant greater improvement in the L-T4-treated group than in the placebo group. In contrast, quadriceps strength did not change after L-T4 or placebo use.

Caraccio and cols., in a double-blind placebo-controlled trial, observed a significant improvement in weakness, fatigue, cramps and paresthesia with L-T4, and no improvement with placebo after six months of treatment (42).

The major limitation of the present study was the great of loss to follow-up throughout the study, which led to a small number of participants at the end of study. This may be partially explained by the rigid exclusion criteria at each clinical evaluation. Also, a high number of patients needed L-T4 dosages $>75 \mu \mathrm{g} /$ day to restore euthyroidism, which was considered progression of disease. The exclusion of these patients was an important cause of loss to follow-up in this study.

The comparison between the initially randomized group and the group that concluded the study did not demonstrate selective loss, which could be responsible for an imbalance in the randomization characteristics. This fact minimizes the impact of the losses in the final results.

In conclusion, the results of the present study indicated that L-T4 may improve some physical aspects of QoL, despite the absence of statistically significant improvement in clinical score. L-T4 had a positive impact in IS but had no impact in other muscle parameters. LT4 treatment for 6 months had little impact in the improvement of psychological aspects in sHT.

Disclosure: we would like to thank Sanofi-Aventis for supplying the tablets throughout the study.

\section{REFERENCES}

1. Kaminsky $\mathrm{P}$, Klein M, Duc M. [Hypothyroid myopathy. Physiopathological approach]. Ann Endocrinol. 1992;53(4):125-32.

2. Horak HA, Pourmand R. Endocrine myopathies. Neurol Clin. 2000;18(1):203-13.

3. Eustatia-Rutten CFA, Corssmit EPM, Pereira AM, Frolicht M, Bax J, Romijn JJA. Quality of life in long term exogenous subclinical hyperthyroidism and the effects of restoration of euthyroidism, a randomized controlled trial. Clin Endocrinol. 2006;64(3):284-91.

4. Hendrick VC, Garrick TR. Endocrine and metabolic disorder. In: Kaplan, Sadock's (editors). Comprehensive Textbook of Psychiatry. 7th Ed. Philadelphia: Lippincott Williams \& Wilkins; 2000. p. 1808-13.

5. Smith JW, Evans AT, Costall B, Smythe JW. Thyroid hormones, brain function and cognition: a brief review. Neurosci Biobehav Rev. 2002;26(1):45-60.

6. Cooper DS, Biondi B. The clinical significance of subclinical thyroid dysfunction. Endocr Rev. 2008;29(1):76-131.

7. Cooper DS, Halpern R, Wood LC, Levin AA, Ridgway EC. L-Thyroxine therapy in subclinical hypothyroidism: a double-blind, placebo-controlled trial. Ann Intern Med. 1984;101(1):18-24.

8. Staub JJ, Althaus BU, Engler H, Ryff AS, Trabucco P, Marquardt K, et al. Spectrum of subclinical and overt hypothyroidism: effect on thyrotropin, prolactin, and thyroid reserve, and metabolic impact on peripheral target tissues. Am J Med. 1992;92(6):631-42.

9. Canaris GJ, Manowitz NR, Mayor G, Ridgway C. The Colorado thyroid disease prevalence study. Arch Intern Med. 2000;160(4):526-34.

10. Kong WM, Sheikh MH, Lumb PJ, Naoumova RP, Freedman DB, Crook $\mathrm{M}$, et al. A 6-month randomized trial of thyroxine treatment in women with mild subclinical hypothyroidism. Am J Med. 2002;112(1):348-54.

11. Reuters VS, Buescu A, Reis FA, Almeida CP, Teixeira PF, Costa AJ, et al. avaliação clínica e da função muscular em pacientes com hipotireoidismo subclínico. Arq Bras Endocrinol Metabol. 2006;50(3):523-30.

12. Bianchi GP, Zaccheroni V, Solaroli E, Vescini F, Cerutti R, Zoli M, et al. Health-related quality of life in patients with thyroid disorders. Qual Life Res. 2004;13(1):45-54. 
13. Bell RJ, Rivera-Woll L, Davison SL, Topliss DJ, Donath S, Davis SR. Well-being, health-related quality of life and cardiovascular disease risk profile in women with subclinical thyroid disease - a community-based study. Clin Endocrinol (Oxf). 66(4):548-56.

14. Gulseren S, Gulseren L, Hekimsoy Z, Certinary P, Ozen C, Tokatlioglu B. Depression, anxiety, health-related quality of life, and disability in patients with overt and subclinical thyroid function. Arch Med Res. 2006;37(1):133-9.

15. Monzani F, Caraccio N, Del Guerra P, Casolaro A, Ferrannini E. Neuromuscular symptoms and dysfunction in subclinical hypothyroid patients: beneficial effect of L-T 4 replacement therapy. Clin Endocrinol. 1999;51(2):237-42.

16. Hamilton M. A rating scale for depression. J Neurol Neurosurg Psychiatry. 1960;23:56-62.

17. Hamilton M. The Assessment of Anxiety States by Rating. Br J Med Psychol. 1959;32:50-5.

18. Beck AT, Ward CH, Mendelson M, Mock J, Erbaugh J. An Inventory for Measuring Depression. Arch Gen Psychiatry. 1961;41(4):561-71.

19. Zulewski H, Muller B, Exer P, Miserez AR, Miserez AR, Staub JJ. Estimation of tissue hypothyroidism by a new clinical score: evaluation of patients with various grades of hypothyroidism and controls. J Clin Endocrinol Metab. 1997;82(3):771-6.

20. Ciconelli RM, Ferraz MB, Santos W. Brazilian-Portuguese version of the SF-36. A reliable and valid quality of life outcome measure. Rev Bras Reumatol. 1999;39:143-50.

21. Daniels $L$, Worthingham C. Muscle Testing Techniques of Manual Examination. 3rd ed. Philadelphia:WB Saunders Co; 1972. p. 50-4.

22. Reuters VS, Teixeira PFS, Vigário PS, Almeida CP, Buescu A, Ferreira $\mathrm{MM}$, et al. Exercise tolerance and muscular abnormalities in subclinical hypothyroidism. Am J Med Sci. 2009;338(4):259-63.

23. The National Isometric Muscle Strength (NIMS) Database Consortium. Muscular weakness assessment: use of normal isometric strength data. Arch Phys Med Rehabil. 1996;77:1251-5.

24. Riddoch G, Rowley BW, Cairns HWB. Aids to the investigation of peripheral nerve Injuries. Medical Research Council, London: HM Stationery Office; 1943.

25. Picado C, Fiz JA, Montserrat JM, Grau JM, Fernandez-Sola $\mathrm{J}$, Luengo MT, et al. Respiratory and skeletal muscle function in steroid-dependent bronchial asthma. Am Rev Respir Dis. 1990;141(1):14-20.

26. Black LF, Hyatt RE. Maximal respiratory pressures: normal values and relationship to age and Sex. Am Rev Respir Dis. 1969;99:696-702.

27. Bono G, Fancellu R, Blandini F, Santoro G, Mauri M. Cognitive and affective status in mild hypothyroidism and interactions with L-thyroxine treatment. Acta Neurol Scand. 2004;110 (1):59-66.

28. Jorde R, Waterloo K, Storhaug H, Nyrnes A, Sundsfjord J, Jenssen TG. Neuropsychological function and symptoms in subjects with subclinical hypothyroidism and the effect of thyroxine treatment. J Clin Endocrinol Metab. 2006;91(1):145-53.

29. Jensovsky J, Ruzicka E, Spackova N, Hejdukova B. Changes of event related potential and cognitive processes in patients with subclinical hypothyroidism after thyroxine treatment. Endocr Regul. 2002;36(3):115-22.

30. Baldini IM, Vita A, Mauri MC, Amodei V, Carrisi M, Bravin S, et al. Psychopathological and cognitive features in subclinical hypothyroidism. Prog Neuropsychopharmacol Biol Psychiatry. 1997;21(6):925-35.

31. Almeida CP, Brasil MA, Costa AJL, Reis FAA, Reuters VS, Teixeira PFS, et al. Subclinical hypothyroidism: psychiatric disorders and symptoms. Rev Bras Psiquiatr. 2007;29:157-59.

32. Teixeira PFS, Reuters VS, Almeida CP, Ferreira MM, Wagman $\mathrm{MB}$, Reis FAA, et al. Avaliação clínica e de sintomas psiquiátricos no hipotireoidismo subclínico. AMB Rev Assoc Med Bras. 2006;52:222-8.

33. Çakmak G, Saler T, Saðlam ZA, Yenýgün M, Demýr T. Spirometry in patients with clinical and subclinical hypothyroidism. Tuberk Toraks. 2007;55(3):266-70.

34. Koral L, Zeliha H, CetinY, Bilgin O, ArzuY, Alpaslan G. Does thyroid replacement therapy affect pulmonary function tests in patients with subclinical hypothyroidism? Saudi Med J. 2006;27(3):329-32.

35. Jaeschke R, Guyatt G, Cook D, Harper S, Gerstein HC. Spectrum of quality of life impairment in hypothyroidism. Qual Life Res. 1994;3(5):323-7.

36. Razvi S, Ingoe L, Keeka G, Oates C, McMillan C, Weaver JU. The beneficial effect of I-Thyroxine on cardiovascular risk factors, endothelial function, and quality of life in subclinical hypothyroidism: randomized, crossover trial. J Clin Endocrinol Metab. 2007;92(5):1715-23.

37. Simonsick EE, Newman AB, Ferrucci $L$, Satterfield $S$, Harris TB, Rodondi N, et al. Subclinical hypothyroidism and functional mobility in older adults. Arch Intern Med. 2009;169(21):2011-7.

38. ParkYJ, Lee EJ, LeeYJ, Choi SH, Park JK, Lee SB, et al. Subclinical hypothyroidism $(\mathrm{SCH})$ is not associated with metabolic derangement, cognitive impairment, depression or poor quality of life (QoL) in elderly subjects. Arch Gerontol Geriatr. 2010;50(3):e 68-73.

39. Sichieri R, Baima J, MaranteT, Vasconcellos MTL, Moura AS, Vaisman M. Low prevalence of hypothyroidism among black and Mulatto people in a population-based study of Brazilian women. Clin Endocrinol. 2007;66(6):803-7.

40. Meier C, Staub JJ, Roth CB, Guglielmetti M, Kunz M, Miserez AR, et al. TSH-controlled L-thyroxine therapy reduces cholesterol levels and clinical symptoms in subclinical hypothyroidism: a double blind, placebo-controlled trial (Basel Thyroid Study). J Clin Endocrinol Metab. 2001;86(10):4860-66.

41. Nyström E, Caidahl K, Fager G, Wikkelsö C, Lundberg PA, Lindstedt GA. A double-blind cross-over 12-month study of L-thyroxine treatment of women with 'subclinical' hypothyroidism. Clin Endocrinol. 1988;29(1):63-75.

42. Caraccio N, Natali A, Sironi A, Baldi S, Frascerra S, Dardano A, et al. Muscle metabolism and exercise tolerance in subclinical hypothyroidism: a controlled trial of levothyroxine. J Clin Endocrinol Metab. 2005;90:4057-62. 